\title{
Vaginal Infection, CTCAE
}

National Cancer Institute

\section{Source}

National Cancer Institute. Vaginal Infection, CT CAE. NCI Thesaurus. Code C143924.

A disorder characterized by an infectious process involving the vagina. 